\title{
HARMONISING THE TRAINING OF STUDENTS WITHIN THE EU TO IMPLEMENT INTERVENTION PROGRAMMES TO PROTECT THE PUBLIC IN THE AFTERMATH OF A HAZMAT INCIDENT
}

\author{
A. Peña-Fernández ${ }^{1}$, L.J. Dunford ${ }^{1}$, P.I. Haris ${ }^{1}$, M.C. Lobo-Bedmar ${ }^{2}$, M.A. Peña ${ }^{3}$ \\ ${ }^{1}$ Faculty of Health and Life Sciences, De Montfort University, The Gateway (UNITED \\ KINGDOM) \\ ${ }^{2}$ Departamento de Investigación Agroambiental. IMIDRA (SPAIN) \\ ${ }^{3}$ Unidad de Farmacia y Tecnología Farmacéutica, Departamento de Ciencias Biomédicas \\ Universidad de Alcalá (SPAIN)
}

\begin{abstract}
The increasing frequency of incidents involving hazardous materials (HazMat) encompassing a wide range of chemical and biological environmental contaminants shows a need to teach environmental toxicology, public health and emergency preparedness to future health care professionals to protect the public. Serious HazMat incidents present an enormous challenge in the health care sector and may involve national and international health service collaboration requiring specific training. The development of educational programmes for health care professionals to manage serious HazMat incidents is needed and this should be harmonised within the EU. Moreover, the pharmaceutical and chemical industries in conjunction with the public health sector are demanding professionals with specific knowledge to respond to HazMat events and deal with environments seriously impacted by chemical or biological incidents that can threaten human health. Future professionals will need specific knowledge to implement different intervention strategies for health protection. Our teaching innovation group is developing a series of novel teaching sessions including short courses, lectures, workshops and tutorials, to train undergraduate and postgraduate health science students in these topics in two EU Universities: University of Alcalá (UAH, Spain) and De Montfort University (DMU, UK). We are using guidelines from organisations such as The Environmental Protection Agency and Centres for Disease Control and Prevention in the US, the UK National Health Service, as well experience from the field gained from the recent Ebola outbreak in West Africa. Additionally, a combination of different pedagogic approaches are being used, e.g. "peer teaching" (Benè and Bergus, 2014) or ProblemBased Learning (PBL) to create a variety of teaching materials and sessions. These pedagogic approaches were adapted for a diverse student cohort with limited knowledge of environmental toxicology, emergency preparedness and risk assessment. Specifically, we created a specialised short training course in environmental toxicology for pharmacists at UAH (Peña-Fernández et al., 2015), which was improved for the 2015/16 academic session using students' feedback from the previous course. This was also delivered to undergraduate (BMedSci. Medical Sciences) and postgraduate (MSc. Advanced Biomedical Science) students at DMU. The main objective of these teaching sessions was to provide the students with basic knowledge to implement an intervention programme to protect the public in the aftermath of a HazMat incident or a pandemic outbreak. All the teaching sessions and materials were highly interactive, requiring a high level of participation and preparation from the students due to their short duration. Despite their short duration we observed high levels of student engagement/satisfaction (e.g. nearly $100 \%$ from pharmacists attending the training course at UAH this year). The novel teaching sessions created at both universities could effectively provide students with public health knowledge and tools to develop a response and preparedness for intervention against chemical or biological events. This communication will describe the different teaching activities and students' feedback/opinions collected at both participating universities for 2015/16. We consider that this training programme could be used to develop appropriate training to health care professionals in the EU.
\end{abstract}

Keywords: Undergraduate and postgraduate training, public health, environmental toxicology, HazMat management.

\section{INTRODUCTION}

Recent global health threats from bioterrorism to the Ebola outbreak in West Africa have shown that there is a necessity for teaching public health and medical preparedness to future health care 
professionals in order to protect public health against these global threats. Moreover, teaching global health is critical as the world has become an interdependent global community, sharing similar health issues and public health functions [1].

Specific global health threats that can have a high impact in the morbidity and mortality of the population are incidents or accidents involving hazardous materials (HazMat) from any chemical, biological, radiological, and nuclear (CBRN) source. Although CBRN/HazMat incidents could involve the same substance, agent or material, HazMat normally is used when the release is accidental or involuntary and CBRNe (Chemical Biological Radiological Nuclear and explosive) when it is deliberate.

Human health care professionals and other first responders to CBRN/HazMat incidents require high specialised preparedness and resources to respond to them in order to protect public health. This will be particularly critical for medical and health care professionals, although there is very little specific training available for them to respond to these types of events within the European Union (EU) as reported elsewhere [2]. Because of this, several measures are being undertaken to address this gap or improve the already emergency preparedness and capacity to respond to CBRN/HazMat incidents, and this will be particularly necessary in hospitals as they will be one of the first and main responders against any CBRN emergency [3]. Thus, the European Commission is funding an EU project to identify health care professionals' educational needs named Integrated Strategy for CBRN threat identification and emergency response (TIER) [4]. This is because an appropriate and specialised expertise to respond to CBRN/HazMat emergencies in human health care professionals is critical as this can have significant consequences for the morbidity and mortality of the population [5] as well as societal implications. Therefore, specific skills and capabilities are required for efficient response to these types of events as highlighted in a recent article published by Olivieri et al. (2016) [6].

The response of hospitals to CBRN emergencies and casualties also need to be standardised to be more specific although it has been described that there is some level of discrepancy between different hospitals in the same country. This is, for example, the case of Finland, in which Jama et al. (2016) [2] have pointed out that some specific hospitals in Finland would have a better clinical capacity than others after studying 20 hospital districts. Mortelmans et al. (2014) have also reported gaps in hospital preparedness in the aftermath of a terrorist attack or accidental event involving CBRN substances [3].

As highlighted previously, a recent EU study has identified and described specific competences and skills that any human health care professionals in a hospital would need to have to respond appropriately to CBRN incidents [4]. These competences should be taken into consideration to train professionals at any EU hospital. More resources should be put in place as time, resources and appropriate skills to train first responders in the aftermath of an incident involving CBRN substances or agents are frequently described as a challenge or a barrier [3] in the delivery of high standard training that could be critical to save and protect large groups of a population.

The public health sector is increasingly demanding health care professionals and health professionals with a knowledge and training to respond to HazMat events that can place a population at risk [7]. Moreover, those future professionals should be equipped with evidence based and analytical skills to advocate for public health interventions that, in turn, will help patients and communities. Moreover, by teaching public health and health interventions, medical sciences students not only will achieve a better educational outcome to inform on future patient treatment but also for living a healthier life.

Our teaching innovation group is developing a series of novel teaching sessions including short courses, lectures, workshops and tutorials, to train undergraduate and postgraduate health science students regarding how to implement appropriate, feasible and applicable intervention programmes to protect the public in the aftermath of a HazMat/CBRN incident in two EU Universities: University of Alcalá (UAH, Madrid, Spain) and De Montfort University (DMU, Leicester, United Kingdom). To create these teaching sessions, we have followed guidelines from different organisations such as The Environmental Protection Agency and Centres for Disease Control and Prevention in the United States (US); or the National Health Service and Public Health England in the United Kingdom (UK).

Additionally, we have adapted different pedagogic approaches for a diverse student cohort with limited knowledge of environmental toxicology, emergency preparedness and risk assessment (such as pharmacists or medical science students). Specifically, we have adopted the "peer teaching" pedagogy described by Benè and Bergus (2014) [8] and the Problem-Based Learning (PBL) described by Jones et al. (2010) [9] to create a variety of teaching materials and sessions. 
Finally, we have also used experience from the field gained from the recent Ebola outbreak in West Africa, to create different workshops [10].

This communication will provide a description of the different teaching activities and students' feedback/opinions collected at both participating universities for 2015/16 as well as different improvements and activities that will be undertaken in the next academic year 2016/17. A complete implementation of these teaching activities and a comprehensive assessment of the teaching materials and students' satisfaction will be also undertaken in 2016/17 through using validated feedback-questionnaires following previous similar experiences at UAH [11]. This analysis is critical to establish whether the created training will be successful to train future medical science students in some basic skills in public health and medical preparedness to protect the public in the aftermath of a HazMat incident.

\section{TRAINING TO IMPLEMENT INTERVENTION PROGRAMMES IN THE AFTERMATH OF A HAZMAT INCIDENT}

Teaching global public health or medical preparedness in the aftermath of a HazMat/CBRN event is very minimal or practically non-existent at DMU (UK). To address this gap, several initiatives have been put in place during the academic course 2015/16, particularly in the Medical Science degree programme and in the MSc. Advanced Biomedical Science at DMU. These initiatives include: the creation of two completely new modules, named Clinical Perspectives I and II (which are taught to second- and third-year undergraduate students); and the re-structured and improved version of the former module "Evidence Based Medicine" (which is taught to second-year students). In addition, a series of specialised workshops have been created by lecturers with a public health background following a previous successful experience to create a short training course/workshop to train pharmacists in risk assessment and environmental toxicology [10]. The specialised workshops were created and delivered to provide those DMU students with basic knowledge to implement an intervention programme to protect the public in the aftermath of a HazMat/CBRN incident or a pandemic outbreak.

\subsection{Core competences for medical scientists to be involved in the response of a HazMat/CBRN incident}

We have taken into consideration some of the core competences that any medical first responder to CBRN emergencies should have, competences that have been identified in the TIER project [4]. The competences that we have considered as appropriate for Medical Science students have been also modified to suit the skills of our students vs. medical students; e.g. medical science students have not received full training in clinical skills. Moreover, we have considered that to have basic knowledge of environmental toxicology and public health would be critical for first responders in the aftermath of a CBRN incident and we have considered these skills in the development of our workshops. Thus, the competences that we have considered are collected and described in Table 1.

Table 1. Topics and core competences that we have considered as useful for future medical scientists in relation to CRBN/HazMat response (some of the content has been adapted from Djalali et al., 2016

[4]).

\begin{tabular}{|c|c|}
\hline Domain (Topic) & Core competences \\
\hline \multirow[t]{4}{*}{$\begin{array}{l}\text { Identification of the risk and } \\
\text { risk analysis }\end{array}$} & $\begin{array}{l}\text { Basic understanding of what CBRN substances, agents or products } \\
\text { are. }\end{array}$ \\
\hline & Characteristics of common environmental pollutants or hazards. \\
\hline & $\begin{array}{l}\text { Demonstrate proficiency in the description of the source-pathway- } \\
\text { receptor model. }\end{array}$ \\
\hline & $\begin{array}{l}\text { Elementary introduction to the risk assessment tool developed by the } \\
\text { US Environmental Protection Agency (US EPA) [11]) }\end{array}$ \\
\hline
\end{tabular}




\begin{tabular}{|c|c|}
\hline $\begin{array}{l}\text { Toxicological effect of CBRN } \\
\text { agents }\end{array}$ & $\begin{array}{l}\text { Basic understanding of what is a toxic, carcinogenic or genotoxic } \\
\text { substance and an, endocrine disruptor. } \\
\text { Understand the difference between acute and chronic. } \\
\text { Basic understanding of principles of environmental toxicology and why } \\
\text { protection of our environment is essential. } \\
\text { Demonstrate proficiency in describing different human exposure } \\
\text { sources to HazMat substances. }\end{array}$ \\
\hline $\begin{array}{l}\text { Planning and organisation of } \\
\text { an intervention programme }\end{array}$ & $\begin{array}{l}\text { An understanding of the general UK response and preparedness } \\
\text { against biological or chemical incidents. } \\
\text { Basic understanding of medical response and recovery in respect of } \\
\text { CBRN casualties, including protection measures that health care } \\
\text { professionals need to follow to protect themselves. } \\
\text { Demonstrate proficiency in using an Evidence Based Public Health } \\
\text { approach to develop an appropriate intervention programme to protect } \\
\text { human health. } \\
\text { Demonstrate proficiency in identifying successful intervention } \\
\text { programmes in the literature, and undertake analytic and well- } \\
\text { documented decisions. } \\
\text { Demonstrate proficiency in identifying special health needs according } \\
\text { to age, gender, population, country. } \\
\text { Demonstrate proficiency in identifying basic consumables and } \\
\text { resources that would be necessary in laboratories that are working in } \\
\text { response to stop the spread of highly contagious microorganisms. } \\
\text { A basic understanding in selecting basic decontamination options to } \\
\text { address different environments impacted by chemical and biological } \\
\text { substances (specifically the following environments: soil, drinking water } \\
\text { system, food production systems, hospitals and laboratories surfaces). }\end{array}$ \\
\hline $\begin{array}{l}\text { Communication and } \\
\text { information management }\end{array}$ & $\begin{array}{l}\text { An understanding of how to communicate to the public any } \\
\text { CBRN/HazMat incident to reduce to a minimum panic and terror, social } \\
\text { disruptions or ethical issues. } \\
\text { An understanding of societal and ethical factors that may affect the } \\
\text { success of an intervention programme. } \\
\text { Demonstrate proficiency in understanding communications that have } \\
\text { been put in place in real CBRN/HazMat events; and identification of } \\
\text { weaknesses that may result in a disadvantage or barrier to the } \\
\text { intervention programme developed. }\end{array}$ \\
\hline $\begin{array}{l}\text { Safety and personal protective } \\
\text { equipment (PPE) }\end{array}$ & $\begin{array}{l}\text { Demonstrate an understanding in principles and methods of safety, } \\
\text { personal security and integrity of medical/biomedical scientists that are } \\
\text { dealing with a CBRN agent. } \\
\text { An understanding of the appropriate PPE for health care and laboratory } \\
\text { professionals during the implementation of the intervention programme. } \\
\text { A basic understanding of the decontamination procedures for CBRN } \\
\text { patients and hospital \& laboratory environment. }\end{array}$ \\
\hline Societal and ethical reflexions & $\begin{array}{l}\text { An understanding of the different nationalities, ethnicities and } \\
\text { backgrounds to make sure that the intervention programme will protect } \\
\text { all ages, populations and communities affected by a CBRN incident. }\end{array}$ \\
\hline
\end{tabular}

\subsection{Workshops and novel training developed at the University of Alcalá (Spain) and at De Montfort University (UK)}

Our teaching innovation group has created the following novel teaching sessions following previous experiences $[10,12,13]$, the competences described in Table 1 and different pedagogical approaches highlighted above: 
a) Workshops to develop an intervention programme in the aftermath of a pandemic outbreak affecting a whole country such as for example the UK. The outbreaks were produced by Ebola and Zika virus. We have followed our experience as Biomedical Scientists at the PHE Ebola laboratory at Makeni, Sierra Leone, West Africa, during the recent Ebola outbreak. Comprehensive information about the development of this workshop is collected in PeñaFernández and Choi (2016) [12]. The workshop was delivered to students enrolled in Clinical Perspectives II in 2015/16, and the students' feedback recorded through Blackboard to evaluate the whole module has been very positive, although more comprehensive feedback will be collected in the next academic session after gaining ethical approval by the Research Ethics Committee at DMU (Ref. 1729; 14th September 2016) to distribute validated feedbackquestionnaires specifically designed by our teaching group.

b) The specialised short training course in environmental toxicology developed for pharmacists at UAH (Spain) [10], and recently improved following students' feedback [13], was adapted to create different lectures and a workshop for postgraduate students attending the MSc. Advanced Biomedical Science at DMU (UK). Masters degree students at DMU completed an intervention programme to protect public health in the aftermath of a HazMat affecting the food chain. Ten students were enrolled in this MSc in 2015/16; students worked in pairs and undertook the following tasks (which follow some of the competences detailed in Table 1): i) identify the chemicals involved in the incident and evaluate if they were toxic/carcinogenic for humans; ii) highlight possible risks for human health according to the chemicals involved and the scenario (environment) affected; iii) tailor an intervention programme to decontaminate the food production system affected and actions to protect human health (e.g. some of the contaminants may have passed to the food chain and could have potentially become available in different supermarkets). Students worked on computers using the novel recovery tool developed by Public Health England $[14,15,16]$.

c) A simplified workshop was created for second year Medical Science students attending the module "Evidence Based Medicine". These students were provided with different materials to develop an intervention programme to protect children from a highly contaminated playground; the scenario was collected following a real case in the UK [17]. Comprehensive information about this workshop has been previously described [18]. A specific feedback questionnaire has also been developed to assess the success of this workshop; this, questionnaire will be distributed next academic year, and can be found in Table 2 .

Table 2. Feedback questionnaire to measure the degree of satisfaction of the teaching-learning process of the workshop involving metals in a playground.

\begin{tabular}{|l|}
\hline \multicolumn{1}{|c|}{ Questionnaire } \\
\hline The content was relevant to the module \\
\hline The duration of the workshops was appropriate \\
\hline Overall, I enjoyed the different exercises \\
\hline The articles and exercises were easy to understand \\
\hline The workshop lead in the environment helped me to understand the need for global intervention \\
\hline I understand how to carry out an Evidence Based Public Health study to identify public health interventions \\
\hline I have learnt how to protect children from environmental contaminants such as lead \\
\hline My knowledge in public health has improved \\
\hline I am satisfied with the workshops provided \\
\hline I think that the knowledge learnt in the workshops will help me in my future career \\
\hline I would recommend the incorporation of more similar workshops within the Medical Sciences programme \\
\hline What would you add or remove from this training? \\
\hline Any other comments or suggestions for future years? \\
\hline
\end{tabular}




\section{CONCLUSIONS}

Our development of teaching materials for life science students in the UK and Spain is an attempt towards harmonisation of training of students within the EU to tackle incidents involving hazardous materials encompassing a wide range of chemical and biological environmental contaminants. A comprehensive evaluation of students performance and feedback will need to be collected to determine whether these teaching sessions and practice will be successful for teaching medical preparedness and public health to future medical science students (and if students acquire the competences described in Table 1 at the end of their degree). On the basis of our experience thus far, the following outcomes can be highlighted:

1 Students have gained some public health knowledge and an awareness of global determinants of health and their impacts [19].

2 Students were able to have a clear picture of the UK response and preparedness against biological events, such as for example what will be done in the hypothetical scenario of a infectious disease outbreak.

3 These workshops have shown to be effective to facilitate the acquisition of different transversal competences such as critical thinking, research skills (e.g. analysing and understanding research articles), communication and team work, using evidence-based educational practice, etc. These competences are key for professional health workers but also will allow students to take responsibility for their own learning experience.

\section{ACKNOWLEDGEMENTS}

We would like to thank everyone in the PHE Ebola Deployment team for the opportunity of working in their mobile laboratory at Makeni, Sierra Leona (West Africa) during the Ebola outbreak. The authors would like to express their sincere appreciation to Dr. Mark D. Evans (De Montfort University) for his advice and writing assistance.

\section{REFERENCES}

[1] Jackson SF and Cole DC. Graduate global public health education: activities and outcomes in relation to student prior experience. Glob J Health Sci 2013; 5(3):54-63.

[2] Jama TJ, Kuisma MJ. Preparedness of Finnish Emergency Medical Services for Chemical Emergencies. Prehosp Disaster Med 2016; 31(4):392-6.

[3] Mortelmans LJ, Van Boxstael S, De Cauwer HG, Sabbe MB; Belgian Society of Emergency and Disaster Medicine (BeSEDiM) study. Preparedness of Belgian civil hospitals for chemical, biological, radiation, and nuclear incidents: are we there yet? Eur J Emerg Med 2014; 21(4):296-300.

[4] Djalali A, Della Corte F, Segond F, Metzger MH, Gabilly L, Grieger F, Larrucea X, Violi C, Lopez $C$, Arnod-Prin P, Ingrassia PL. TIER competency-based training course for the first receivers of CBRN casualties: a European perspective. Eur J Emerg Med. 2016 Feb 26. DOI: 10.1097/MEJ.0000000000000383.

[5] Van der Woude I, de Cock JS, Bierens JJ, Christiaanse JC. TAP CBRN preparedness: knowledge, training and networks. Prehosp Disaster Med 2008; 23:s65-s69.

[6] Olivieri C, Ingrassia PL, Della Corte F, Carenzo L, Sapori JM, Gabilly L, Segond F, Grieger F, Arnod-Prin P, Larrucea X, Violi C, Lopez C, Djalali A. Hospital preparedness and response in CBRN emergencies: TIER assessment tool. Eur J Emerg Med. 2016 Apr 7. DOI: 10.1097/MEJ.0000000000000399

[7] Hogan $\mathrm{H}$ and Haines $\mathrm{A}$. Global health: a positive addition to public health training? J Public Health (Oxf) 2011; 33(2):317-8.

[8] Benè KL. and Bergus G. When learners become teachers: a review of peer teaching in medical student education. Fam Med 2014; 46(10):783-7.

[9] Jones NL, Peiffer AM, Lambros A, Guthold M, Johnson AD, Tytell M, Ronca AE, Eldridge JC. Developing a problem-based learning (PBL) curriculum for professionalism and scientific integrity training for biomedical graduate students. J Med Ethics 2010; 36(10):614-9. 
[10] Peña-Fernández A., González-Muñoz M.J., Peña M.A. Designing training for teaching environmental toxicology to specialised pharmacists. Currents in Pharmacy Teaching and Learning 2015; 7(6):864-868.

[11] US EPA. Risk Assessment Guidance for Superfund. Volume 1: Human Health Evaluation Manual (Part A), 1989. EPA/540/1-89/002, Office of Emergency and Remedial Response.

[12] Peña-Fernández A. and Choi EML. Novel methods of teaching evidence-based medicine and public health: experience from the field during the Ebola outbreak. Submitted for publication to the 9th annual International Conference of Education, Research and Innovation (ICERI 2016). In press.

[13] Peña-Fernández A., Escalera Izquierdo B., Peña MA. Analysis of teaching workshop in environmental toxicology in the Pharmacy specialty Industrial Pharmacy and Galenicals. XIV Conference of Research Networks on University Teaching 2016: 1389-1398, Alicante, Spain. ISBN: 978-84-608-7976-3. Available at: http://rua.ua.es/dspace/handle/10045/57093 (in Spanish)

[14] Public Health England. Chemical Recovery Navigation Tool. Available at: https://www.gov.uk/government/publications/chemical-and-radiation-recovery-navigation-tool-crrnt [accessed 21/09/2016]

[15] Peña-Fernández A., Wyke S., Brooke N., Duarte-Davidson R. Factors influencing recovery and restoration strategies following a chemical incident. Environment International 2014; 72:98-108.

[16] Wyke S., Peña-Fernández A., Brooke N., Duarte-Davidson R. The importance of evaluating the physicochemical and toxicological properties of a contaminant for remediating environments affected by chemical incidents. Environment International 2014; 72:109-118.

[17] Turner A, Kearl ER, Solman KR. Lead and other toxic metals in playground paints from South West England. Sci Total Environ. 2016; 544:460-6.

[18] Peña-Fernández A., Peña MA., Lobo-Bedmar MC., Evans MD. New challenges for environmental toxicology education in the European Union. Submitted for publication to the 9th annual International Conference of Education, Research and Innovation (ICERI 2016). In press.

[19] Lee AC, Hall JA, Mandeville KL. Global public health training in the UK: preparing for the future. J Public Health (Oxf) 2011; 33(2):310-6. 